\title{
Deciduogenic effect of prostaglandins in the pseudopregnant rabbit
}

\author{
L. H. Hoffman, G. B. Strong, G. R. Davenport and J. C. Frölich \\ Departments of Anatomy and Pharmacology, Vanderbilt University School of Medicine, Nashville, \\ Tennessee 37232, U.S.A.
}

\begin{abstract}
Summary. Intrauterine implants made of Silastic or wax and containing various additives, including prostaglandins (PGs), were used to characterize some of the factors involved in deciduogenesis in rabbits. Implants were inserted into uteri on Day 6 of pseudopregnancy and the response was assessed by light microscopy on Day 10 . The surface area of decidual tissue in histological sections was employed as an index of the degree of decidualization obtained. PGE-2, PGF-2 $\alpha$ and arachidonic acid each elicited a prominent decidual response, $P$ GE- 2 being the most potent. Implants which released histamine or oestradiol-17 $\beta$ had a very slight decidualizing effect in some females. Control implants and implants releasing dibutyryl cyclic-AMP had no deciduogenic influence. All implants, regardless of additive content, induced a symplasmic transformation of the uterine surface epithelium. It is concluded that PGs and the distension caused by the implant may be involved in deciduogenesis in the rabbit.
\end{abstract}

\section{Introduction}

Interaction of a blastocyst with the hormonally conditioned uterus of mammals results in a dramatic series of structural and functional changes in the endometrium. In the rabbit, one of the most predictable reactions is the decidual cell response (DCR) resulting in massive perivascular cuffs of modified stromal cells laden with glycogen and other cytoplasmic inclusions. Numerous investigators have utilized the production of deciduomata in experimental animals as an analogue for normal ovoimplantation; however, mammals differ in their sensitivity to various decidualizing stimuli. In some, like the rat and mouse, a wide variety of chemical and mechanical stimuli result in a prominent DCR (DeFeo, 1967). The rabbit uterus appears to be somewhat less sensitive to many of these deciduogenic stimuli. Although endometrial trauma (Beasley \& Davenport, 1970) and certain chemical stimuli (Elton, 1966) result in a moderate DCR, the results of traumatic stimulation are often less than satisfactory. The blastocyst, even when dispensed with by postimplantation destruction, is by far the best stimulus for inducing a DCR in rabbits (Hoffman \& Davies, 1971).

In addition to decidualization, blastocyst interaction with the uterus induces a local increase in vascular permeability (Psychoyos, 1971) and, in the rabbit, induces an epithelial transformation resulting in a syncytium of uterine epithelial cells referred to as the maternal symplasma (Amoroso, 1952).

The present study is an attempt to characterize the stimuli involved in symplasma production and induction of the DCR in uteri of pseudopregnant rabbits.

\section{Materials and Methods}

New Zealand White rabbits weighing $3 \cdot 5-4 \cdot 5 \mathrm{~kg}$ were used. Pseudopregnancy was induced by the injection on Day 0 of 50 i.u. HCG into the marginal ear vein. On Day 6 females were anaesthetized with sodium pentobarbital (Nembutal: Abbott) and the reproductive tract exposed through a midventral incision. Ovaries were inspected for the presence of recent corpora lutea (CL). A small incision was made in each uterine horn and the wax or Silastic implants (described below) were inserted. 
The implants were manipulated to a distance of 2 or $3 \mathrm{~cm}$ from the uterine incision and then held in place with loose silk ligatures which passed around the uterine horns. The tightness of the ligatures was such that the intramural vascular supply would not be compromised. The uterine incision was closed with fine chromic sutures and the abdominal incision with silk sutures. An experimental (additive-containing) implant was placed in one uterine horn of each female, while the opposite (control) horn received a similar implant lacking the additive. Each female received $15 \mathrm{mg}$ oxytetracycline hydrochloride (Liquamycin: Pfizer) after operation.

Females were killed on Day 10 of pseudopregnancy. The intrauterine implants were removed and samples of the uterus from implant and non-implant areas were preserved in Bouin's fixative. Specimens were embedded in paraffin wax and 4-6 $\mu \mathrm{m}$ sections were stained with Weigert's iron haematoxylin and eosin. The CL were dissected from the ovaries and weighed; 2 or $3 \mathrm{CL}$ from each ovary were preserved for histological examination. Mean weights of $C L$ from all animals receiving the same additive were compared with the mean luteal weight from a group of 6 control pseudopregnant females by means of Student's $t$ test.

The degree of decidualization in uterine samples was assessed by surface area determination. Cross-sections of uteri from which implants had been removed were examined microscopically and sections through the centre of the implant area were assayed for DCR. Specimens were enlarged 60 -fold using a microprojector and the decidualized areas were traced on heavy paper. The surface area of this tracing of decidual tissue was determined with the aid of an electronic graphic calculator (Numonics Corp.). After correcting for the enlargement, the area of the DCR was recorded in $\mathrm{mm}^{2}$.

Initial experiments with each additive to be tested were carried out using wax implants. The implants were composed of a $2: 1$ mixture of paraffin wax (m.p. $54-56^{\circ} \mathrm{C}$ ) and lauric acid. Various additives, dissolved in $0.10 \mathrm{ml}$ absolute ethanol, were mixed into the molten wax before pouring it into gelatin capsules $(5 \times 13 \mathrm{~mm})$. An estimate of additive release was made by weighing the wax implants before insertion and again after removal from the uterus on Day 10 (Table1). Although with some additives these initial experiments utilizing wax implants were successful in terms of decidual induction, the implants had certain undesirable features. Most importantly, they did not allow for extraction of the various additives for determination of additive release. Silastic implants were employed in subsequent experiments to enable a more reliable determination of additive release values. Silastic rods were prepared by mixing $0.10 \mathrm{ml}$ ethanol containing enough additive for 4 or 5 implants, or the ethanol alone for control implants, with approximately $1.2 \mathrm{ml}$ Silastic elastomer (Silastic 382, Dow Corning) in a large syringe. After adding the catalyst and stirring, the mixture was forced into the barrels of $1 \mathrm{ml}$ disposable syringes where it was allowed to harden. The rods were cut into cylindrical segments $(4.5 \times 15 \mathrm{~mm})$ which were used as intrauterine implants.

The additives utilized were oestradiol-17 $\beta$, histamine, $\mathrm{N}^{6}, \mathrm{O}^{2}$-dibutyryl adenosine- $3^{\prime}, 5^{\prime}$-cyclic monophosphoric acid (dcAMP; Sigma Chemical Co.), arachidonic acid (Grade II, Sigma), prostaglandin (PG) F-2 $\alpha$ (tromethamine salt) and PGE-2. The amounts of each additive incorporated into implants are given in Table 1. All additives were tested at two different concentrations in the Silastic implants. If a decidual response was obtained with the first dose level tried, the level was decreased for the second series of experiments. If the DCR was poor or absent, a higher concentration of additive was incorporated. Two to five females were tested at each additive concentration in the experiments utilizing Silastic implants.

The quantity of additive released from Silastic implants in the uterus was determined by slicing the implants removed on Day 10 into thin slices and extracting them with absolute ethanol. The values obtained from these extracts were subtracted from the amounts present in extracts from a similar $15-\mathrm{mm}$ sample of the original Silastic rod to give the approximate amount of each additive released during 4 days in utero (Table 1). If extracts of control implants contained material which reacted positively with the assay involved, these values were likewise subtracted from the values for release. The quantities of histamine and oestradiol-17 $\beta$ in ethanol extracts of the implants were determined on a Farrand Spectrofluorometer Mark I (Udenfriend, 1962). Absorption spectra for extracts containing dcAMP were obtained on a Beckman-DB recording spectrophotometer and compared with spectra of appropriate standard solutions according to the method of Robison, Butcher \& Sutherland (1970). Arachidonic acid was assayed by microtitration with standard alkali 
(Dole \& Meinertz, 1960). Implant extracts containing PGE-2 were treated with $2 \mathrm{~N}-\mathrm{KOH}$ in ethanol and the resultant chromogen was determined spectrophotometrically (Bydgeman \& Samuelsson, 1964). PGF-2 $\alpha$ was measured by gas chromatography-mass spectrometry (Frölich, 1976). The Silastic implants were not completely inert chemically. Residual elastomer, or more likely catalyst, in the Silastic interfered to some extent with assays for dcAMP and, to a lesser degree, for prostaglandins. Cook (1975) has reported a similar artefact (u.v. absorption maximum $260 \mathrm{~nm}$ ) due to materials eluted from Dow Corning Silastic materials. This problem was circumvented for the dcAMP implants by forming Silastic rods and soaking them for $48 \mathrm{~h}$ in several changes of ethanol. The rods were then impregnated for $24 \mathrm{~h}$ with dcAMP in ethanol. This procedure eliminated the interference with the spectrophotometric assay for dcAMP.

\section{Results}

The presence of implants in the rabbit uterus from Day 6 until Day 10 of pseudopregnancy resulted in the symplasmic transformation of the epithelium apposed to the implant (Pl. 1, Fig. 3). This was true whether the implants were composed of Silastic or paraffin wax/lauric acid. Some degree of symplasma formation occurred in the luminal epithelium of all endometria apposed to implants, regardless of the presence or absence of additives. The glandular epithelium remained cellular (see Pl. 1, Fig. 3).

Implants containing certain of the additives induced a decidual response in the adjacent endometrium.

In females receiving prostaglandin- or arachidonate-containing implants, a gross hypertrophy of the uterine segment apposed to the implant was evident. When these segments were examined histologically the hypertrophy was most evident in the mesometrial ('placental') folds of the endometrium and consisted largely of decidual tissue (compare Pl. 1, Fig. 1 with Pl. 1, Fig. 2). Results obtained with each of the additives were as follows.

Dibutyryl cyclic AMP had no decidualizing influence (Table 1). The histological appearance of endometrium in experimental uterine horns was similar to that seen in the control horns.

Oestradiol-17 $\beta$ had only a slight decidualizing effect. Small amounts of decidual tissue were seen in all 3 females receiving wax implants and in 4 of the 5 females in which Silastic implants were used (Table 1). The degree of response was similar at low and high release values. Oestradiol was the only additive for which the release from Silastic implants was $100 \%$ during the 4 days in utero.

Histamine gave a variable DCR. Only 3 of the 9 females receiving wax or Silastic implants with histamine had measurable decidual tissue in the uterus (Table 1), and with the exception of one female $\left(D C R=13.6 \mathrm{~mm}^{2}\right)$ the response would be considered poor.

Prostaglandin E-2 was the most potent additive. All 11 females had large quantities of decidual tissue in the endometrium apposed to the implants. There was some evidence for a dose-response relationship between the amount of PGE-2 released and DCR, with the highest release values resulting in larger quantities of DCR (Table 1).

Prostaglandin $F-2 \alpha$ consistently induced a DCR, although the surface area in cross-sections was always less than that obtained with PGE-2. Again a dose-response was observed, low release values of PGF- $2 \alpha$ resulted in smaller amounts of decidual tissue (Table 1 ).

Arachidonic acid induced moderate to large quantities of decidual tissue in all females. Relatively large amounts of the fatty acid ( $\geqslant 2 \mathrm{mg}$ ) were incorporated into most of the implants; however, even when lower levels $(200 \mu \mathrm{g})$ were used, measurable quantities of decidual tissue developed (Table 1).

In all females receiving decidua-inducing implants of PGE-2, PGF-2 $\alpha$ or arachidonic acid the DCR in the experimental uterine horn was confined to the implant area. In addition, approximately $30 \%$ of these females had small quantities of DCR in the contralateral uterine horn, i.e. that portion of endometrium in contact with the control implant. This 'contralateral decidua' was always small, generally $<2 \mathrm{~mm}^{2}$ in surface area. Decidualization was never observed, in either horn, in areas of the uterus distant to implant sites, or around control implants contralateral to uteri containing oestradiol, dcAMP or histamine. 
Table 1. Decidual response in rabbits (no. in parentheses) to silastic or wax implants containing various additives

\begin{tabular}{|c|c|c|}
\hline Additive & $\begin{array}{c}\text { Additive } \\
\text { released }(\mu \mathrm{g})^{*}\end{array}$ & $\begin{array}{l}\text { Decidual area } \\
\left(\mathrm{mm}^{2}\right) \dagger\end{array}$ \\
\hline \multicolumn{3}{|l|}{ dcAMP } \\
\hline Wax, $300 \mu \mathrm{g}(1)$ & 90 & 0 \\
\hline Silastic, $8 \mu \mathrm{g}(3)$ & $6 \cdot 1(5 \cdot 1-7 \cdot 3)$ & 0 \\
\hline Silastic, $135 \mu \mathrm{g}(2)$ & $42(33-51)$ & 0 \\
\hline \multicolumn{3}{|l|}{ Oestradiol-17 $\beta$} \\
\hline Wax, $10 \mu \mathrm{g}(3)$ & $1.3(0.8-1.8)$ & $0.8(0 \cdot 1-1.2)$ \\
\hline Silastic, $8 \mu \mathrm{g}(3)$ & 8.0 & $0.3(0.0-0.9)$ \\
\hline Silastic, $90 \mu \mathrm{g}(2)$ & 90 & $0.65(0 \cdot 1-1 \cdot 2)$ \\
\hline \multicolumn{3}{|l|}{ Histamine } \\
\hline Wax, $4 \mathrm{mg}(1)$ & 560 & 1.8 \\
\hline Silastic, $600 \mu \mathrm{g}(5)$ & $190(120-280)$ & $2 \cdot 7 \ddagger(0-13 \cdot 6)$ \\
\hline Silastic, $4 \mathrm{mg}$ (3) & $370(300-500)$ & $0.03(0-0.1)$ \\
\hline \multicolumn{3}{|l|}{ PGE-2 } \\
\hline Wax, $500 \mu \mathrm{g}(3)$ & $112(60-135)$ & $21 \cdot 3(14 \cdot 8-26 \cdot 0)$ \\
\hline Silastic, $25 \mu \mathrm{g}(3)$ & $13.5(10.0-15 \cdot 1)$ & $10.4(9 \cdot 1-10 \cdot 6)$ \\
\hline Silastic, $250 \mu \mathrm{g}(5)$ & $75(52-143)$ & $20 \cdot 0(8 \cdot 9-36 \cdot 4)$ \\
\hline \multicolumn{3}{|l|}{ PGF-2 $\alpha$} \\
\hline Wax, $500 \mu \mathrm{g}(3)$ & $192(120-260)$ & $9 \cdot 3(4 \cdot 8-14 \cdot 5)$ \\
\hline Silastic, $80 \mu \mathrm{g}(2)$ & $35(30-39)$ & $0.2(0-0.4)$ \\
\hline Silastic, $800 \mu \mathrm{g}(3)$ & $390(317-495)$ & $2 \cdot 3(0.9-3.3)$ \\
\hline \multicolumn{3}{|l|}{ Arachidonic acid } \\
\hline Wax, $20 \mathrm{mg}$ (1) & 2400 & $25 \cdot 2$ \\
\hline Silastic, $200 \mu \mathrm{g}(2)$ & $140(110-170)$ & $2 \cdot 1(0.4-3.8)$ \\
\hline Silastic, $2 \mathrm{mg}(4)$ & $1700(1300-1900)$ & $9 \cdot 7(4 \cdot 2-15 \cdot 9)$ \\
\hline
\end{tabular}

* Average amount of additive released during 4 days in uterus, range in parentheses. Values released from wax implants estimated from implant weight loss. Methods used for determining release values from Silastic implants given in text. $\dagger$ Average surface area, range in parentheses.

$\ddagger$ Only one of five females had a DCR.

For purposes of comparison with PG-induced DCR, surface areas were also determined for sections through the decidual tissue of a 10-day pregnant female and on sections from the uterus of a 10-day pseudopregnant female in which a silk thread had been inserted on Day 6 . The average decidual area was $25.1 \mathrm{~mm}^{2}$ in the pregnant female while the decidual area resulting from thread trauma was only $0.45 \mathrm{~mm}^{2}$. Although there may be a wide variation in the degree of decidualization in normal pregnant females or in 'thread-traumatized' females, these values provide some basis of comparison for the results obtained with various implants.

The various implant additives had no detrimental effects on the corpora lutea (CL) as judged by a statistical comparison of $\mathrm{CL}$ weights. Mean luteal weights from all females receiving implants with a given additive were compared with the value obtained from a group of six normal females on Day

\section{EXPLANATION OF PLATE 1}

Fig. 1. Cross-section of uterus which was in contact with a Silastic implant containing PGE-2 (PGE-2 release $=70 \mu \mathrm{g})$. Note the extensive mesometrial hypertrophy, most of which is due to decidual tissue which had a surface area $>30 \mathrm{~mm}^{2}$. An area comparable to that enclosed by the rectangle is enlarged in Fig. 3. $\mathrm{H} \& \mathrm{E}$, scale $=2 \mathrm{~mm}$.

Fig. 2. Cross-section of same uterine horn as in Fig. 1, but from a region distant from the PGE-2 implant. No hypertrophy or decidual tissue can be seen. $H \& E$, scale $=2 \mathrm{~mm}$.

Fig. 3. Enlargement of area of Fig. 1. Massive cuffs of decidual tissue (D) are seen around the mesometrial vascular channels. Symplasmic epithelium (arrows) is present on both sides of the slit-like uterine lumen (asterisks). Note the retention of cellular characteristics in the epithelium lining the uterine glands (G). $\mathrm{H} \& \mathrm{E}$, Scale $=0.2 \mathrm{~mm}$. 

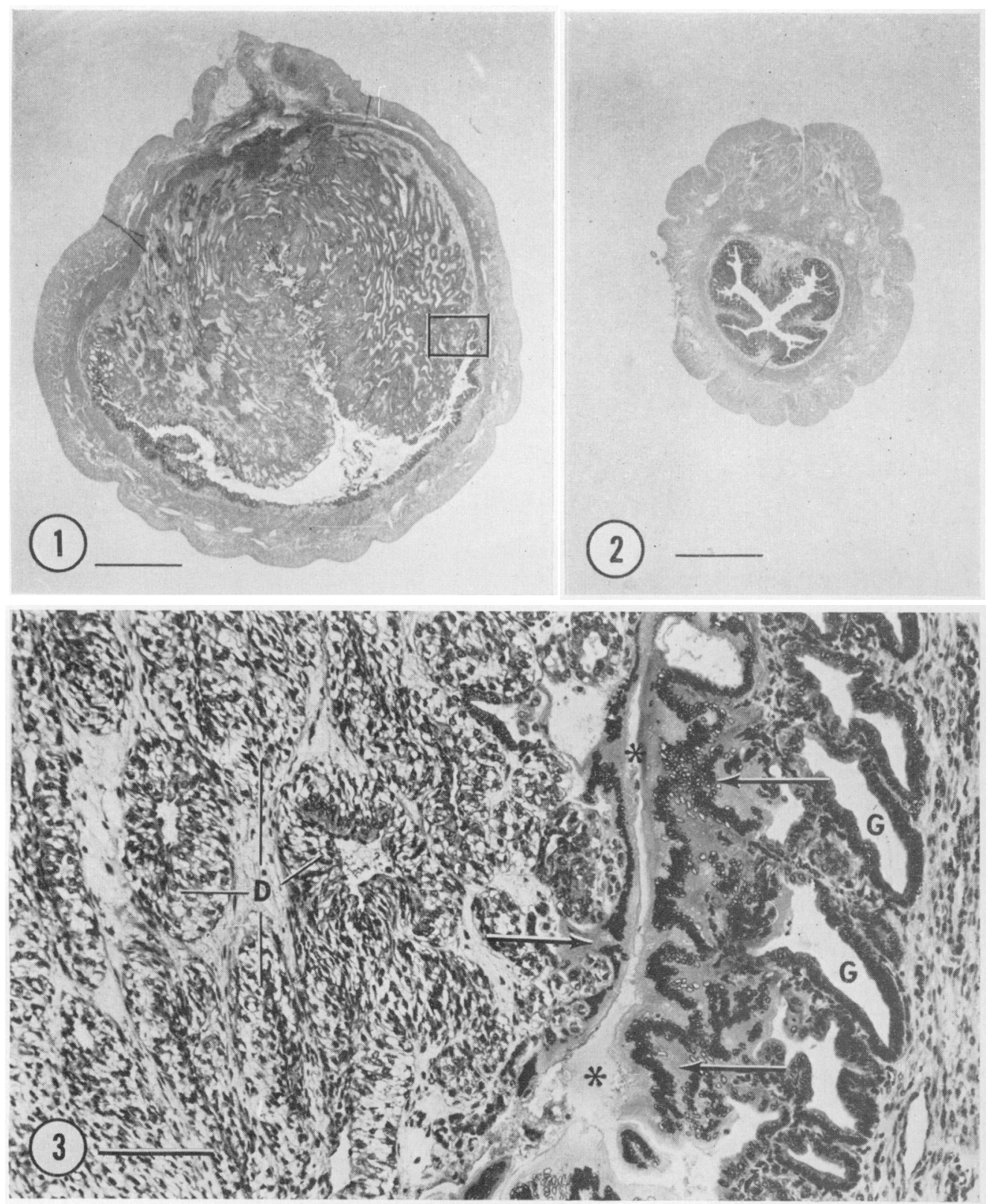
10 of pseudopregnancy (17.6 $\pm 0.9 \mathrm{mg}$, S.E.M.). None of the differences between CL weights in normal psuedopregnancy and those of experimental groups was statistically significant $(P>0.05)$, so the mean CL values have not been included in Table 1. Light microscopic examination of the CL confirmed that there were no consistent histological differences, regardless of the implant additive utilized or the presence or absence of a DCR in a particular female.

\section{Discussion}

The simple columnar surface epithelium of the rabbit uterus changes to a layer of multinucleated cells on Days 6 or 7 of pseudopregnancy or pregnancy (Davies \& Hoffman, 1973), the approximate time of implant insertion in the present study. Progression to the symplasmic condition of the epithelium does not occur in normal pseudopregnancy, only during pregnancy and then only where the epithelium is in contact with the blastocyst, perhaps because of a local (chemical?) effect of the blastocyst (Larsen, 1961). The results of our study indicate that the symplasmic transformation of uterine epithelium in the rabbit is inducible by relatively non-specific stimuli. The distension or endometrial irritation caused by wax or Silastic implants with or without additives results in a prominent development of epithelial symplasma. The significance of the symplasma is unknown for it disappears, along with the bilaminar omphalopleure of the embryo, after the 10th day of gestation in rabbits (Amoroso, 1952).

Elton (1966) was unable to confirm the suggestion of Chambon (1949) that oestrogen was required for rabbit deciduogenesis. Our results indicate that oestradiol has, at best, only a weak decidualizing effect, the DCR induced by this hormone being similar to that induced by thread trauma.

Histamine administration elicits a DCR in pseudopregnant rats (Shelesnyak, 1957), although its physiological role in this process is not universally accepted (Glasser, 1972). Intraluminal injections of histamine failed to trigger a DCR in hormonally primed immature rabbits (Elton, 1966) and our results were inconclusive. As reported for mice (Webb, 1975), dcAMP was ineffective in inducing a DCR in rabbits.

Prostaglandins have not been directly implicated in the induction of decidual development, but Castracane, Saksena \& Shaikh (1974) observed an inhibition of decidual development in pseudopregnant rats receiving indomethacin, suggesting a requirement for physiological levels of PGs in deciduogenesis. Exogenous PGE-2 and PGF-2 $\alpha$ suppressed the DCR in rats, but the effect was thought to be due to PG-induced luteolysis. Although PGF-2 $\alpha$ (Scott \& Rennie, 1970) and arachidonic acid (Hoffman, 1974) are known to be luteolytic in rabbits, no significant changes in luteal weights or histology were observed with these or any of the other implant additives in the present study. This lack of ovarian effect of PGs is probably attributable to the low levels used and the administration of the dose over 4 days. Nevertheless, PGE-2, PGF- $2 \alpha$ and arachidonic acid each elicited a DCR, the response to PGE-2 being the most potent in terms of the quantity of decidual tissue produced.

The occurrence of small amounts of decidual tissue around a few of the control implants contralateral to PG- or arachidonate-containing implants probably indicates an increased systemic concentration of these additives or biologically active metabolites. The uterine horns of the rabbit do not communicate via a common cervix, and we are aware of no evidence for anatomical or functional pathways which would interconnect the horns. Transuterine migration of ova occurs in many other mammals but has not been reported in rabbits (Hafez, 1971). This 'contralateral decidualization' also indicates the contribution of uterine distension to the PG-induced DCR. Additive concentration is presumably elevated in the uterine segments adjacent to the implants, and yet no DCR occurs in the interimplant, i.e. non-distended, areas. Likewise, in the contralateral horn, the DCR was present only in distended regions. We have not tested the effects of these same materials when injected into the uterine lumen, but it seems probable that intraluminal uterine injection of PGs or arachidonic acid would be ineffective in terms of decidual production, or at least less effective than when released from implants. It is of interest that intraluminal instillation of PGF-2 $\alpha$ or arachidonic acid into uteri of 4-day pseudopregnant rats does not augment the DCR obtained after instillation of aqueous 
vehicle only (Tobert, 1976). In the same study, however, Tobert presented evidence supporting a role for PGs in the process of decidualization: when indomethacin was administered $2 \mathrm{~h}$ before or $8 \mathrm{~h}$ after intrauterine instillation of olive oil, the DCR development normally resulting from the oil stimulus was inhibited.

IUDs also produce uterine distension and irritation of the endometrium. Tobert (1975) reported deciduoma formation in pseudopregnant rabbits around IUDs coated with copper but not devices coated with other metals. In view of the enhancement of PGF production by $\mathrm{Cu}^{2+}$ in enzyme preparations from vesicular glands (Lee \& Lands, 1972), the deciduogenic effect of copper might also be related to prostaglandins.

The present study presents the first evidence for a possible PG involvement in rabbit DCR development and appears to be the first direct demonstration that PGs have a deciduogenic effect. In view of the increased vascular permeability induced by certain PGs, in particular those of the $\mathrm{E}$ series (Kaley, Messina \& Weiner, 1972), and the local changes in vascular permeability associated with ovo-implantation/decidualization in mammals (Psychoyos, 1971), the possible association of PGs with decidualizing stimuli seems worthy of further investigation.

We thank Mrs Virginia Winfrey for technical assistance and Dr Kenneth Lau for providing helpful suggestions in the preparation of implants. Dr M. Smigel performed the mass spectrophotometric analysis of PGF-2 $\alpha$. Prostaglandins were generously provided by Dr John Pike, Upjohn Company. This study was supported by NIH Grants HD-05942 and HD-05797 and by the Vanderbilt University Research Council.

\section{References}

Amoroso, E.C. (1952) Placentation. In Marshall's Physiology of Reproduction, Vol. 2, pp. 127-311. Ed. A. S. Parkes. Longmans Green, London.

BEASLEY, S.S. \& DAVENPORT, G.R. (1970) A study of the deciduoma of the pseudopregnant rabbit. Anat. Rec. 166, 276, Abstr.

Bygdeman, M. \& Samuelsson, B. (1964) Quantitative determination of prostaglandins in human semen. Clin. chim. Acta 10, 566-568.

Castracane, V.D., Saksena, S.K. \& Shatkh, A.A. (1974) Effect of IUD's, prostaglandins and indomethacin on decidual cell reaction in the rat. Prostaglandins 6, 397-404.

Chambon, Y. (1949) Essais de réalisation du déciduome en phase progestative par l'administration locale de folliculine chez la lapine. C. r. Séanc. Soc. Biol. 143, $1528-1531$.

Cook, B. (1975) UV-absorbing materials eluted from plastic equipment while collecting rabbit ovarian venous blood. Endocrinology 97, 479-480.

Davies, J. \& Hoffman, L.H. (1973) Studies on the progestational endometrium of the rabbit. I. Light microscopy, day 0 to day 13 of gonadotrophininduced pseudopregnancy. Am. J. Anat. 137, 423446.

DEFEO, V. (1967) Decidualization. In Cellular Biology of the Uterus, pp. 191-290. Ed. R. M. Wynn. Appleton-Century-Crofts, New York.

Dole, V.P. \& MeinerTz, H. (1960) Microdetermination of long-chain fatty acids in plasma and tissues. J. biol. Chem. 235, 2595-2599.

Elton, R.L. (1966) The decidual cell response in rabbits. Acta endocr., Copenh. 51, 543-550.
Frölich, J.C. (1976) Gas chromatography-mass spectrometry of prostaglandins. In The Prostaglandins, Vol. 3 (in press). Ed. P. W. Ramwell. Plenum Press, New York.

Glasser, S. (1972) The uterine environment in implantation and decidualization. In Reproductive Biology, pp. 776-833. Eds H. Balin \& S. Glasser. Excerpta Medica, Amsterdam.

HAFEZ, E.S.E. (1971) Some maternal factors affecting physicochemical properties of blastocysts. In The Biology of the Blastocyst, pp. 139-191. Ed. R. J. Blandau. University of Chicago Press.

Hoffman, L.H. (1974) Luteal regression induced by arachidonic acid in the pseudopregnant rabbit. $J$. Reprod. Fert. 36, 401-404.

Hoffman, L.H. \& Davies, J. (1971) Production of the maternal placenta in rabbits following aspiration of conceptuses. J. Reprod. Fert. 26, 255-257.

Kaley, G., Messina, E.G. \& Weiner, R. (1972) The role of prostaglandins in microcirculatory regulation and inflammation. In Prostaglandins in Cellular Biology, pp. 309-322. Eds P. W. Ramwell \& B. B. Pharriss. Plenum Press, New York.

LARSEN, J.F. (1961) Electron microscopy of the implantation site in the rabbit. Am. J. Anat. 109, 319-334.

LEE, R.E. \& LANDS, W.E.M. (1972) Cofactors in the biosynthesis of prostaglandins $\mathrm{F}_{1 \alpha}$ and $\mathrm{F}_{2 \alpha}$. Biochim. biophys. Acta 260, 203-211.

Psychoyos, A. (1971) Methods for studying changes in capillary permeability of the rat endometrium. In Methods in Mammalian Embryology, pp. 334-338. Ed. J. C. Daniel, Jr. W. H. Freeman \& Co., San Francisco. 
Robison, G.A., Butcher, R.W., \& Sutherland, E.W. (1970) Cyclic AMP, p. 63. Academic Press, New York.

ScorT, R.S. \& RENNIE, P.I.C. (1970) Factors controlling the lifespan of the corpora lutea in the pseudopregnant rabbit. J. Reprod. Fert. 23, 415-422.

ShELESNYA, M.C. (1957) Aspects of reproduction. Some experimental studies on the mechanism of ova implantation in the rat. Recent Prog. Horm. Res. 13, 269-317.

TOBERT, J.A. (1975) Induction of deciduomata by intrauterine copper in the rabbit. J. Reprod. Fert. 45, 197200.
TOBERT, J.A. (1976) A study of the possible role of prostaglandins in decidualization using a nonsurgical method for the instillation of fluids into the rat uterine lumen. $J$. Reprod. Fert. 47, 391393.

UDENFRIEND, S. (1962) Fluorescence Assay in Biology and Medicine, pp. 177-182, 353-359. Academic Press, New York.

WeBb, F.T.G. (1975) The inability of dibutyryl adenosine $3^{\prime}, 5^{\prime}$-monophosphate to induce the decidual reaction in intact pseudopregnant mice. $J$. Reprod. Fert. 42, 187-188.

Received 15 September 1976 